\title{
Intravenous Colistin Use for Multidrug-Resistant Gram-Negative Infections in Pediatric Patients
}

\author{
Ayşe Karaaslan, Eren Çağan, Eda Kepenekli Kadayifci, Serkan Atıcı, Gülşen Akkoç, Nurhayat Yakut, \\ Sevliya Öcal Demir, Ahmet Soysal, Mustafa Bakır
}

Department of Pediatric Infectious Diseases, Marmara University School of Medicine, İstanbul, Turkey

Background: The emergence of infections due to multidrug-resistant Gram-negative bacilli (MDR$G N B)$ has led to the resurrection of colistin use. The data on colistin use and drug-related adverse effects in children are scarce.

Aims: In this study, we aimed to evaluate the clinical efficacy and safety of colistin use in critically ill pediatric patients.

Study Design: This study has a retrospective study design.

Methods: Sixty-one critically ill children were identified through the department's patient files archive during the period from January 2011 to November 2014.

Results: Twenty-nine females and thirty-two males with a mean \pm standard deviation (SD) age of $61 \pm 9$ months (range 0-216, median 12 months) received IV colistin due to MDR-GNB infections. Bacteremia $(\mathrm{n}=23,37.7 \%)$ was the leading diagnosis, followed by pneumonia $(n=19,31 \%)$, clinical sepsis $(n=7,11.4 \%)$, wound infection $(n=6,9.8 \%)$, urinary tract infection $(n=5,8.1 \%)$ and meningitis $(n=1,1.6 \%)$. All of the isolates were resistant to carbapenems; however, all were susceptible to colistin. The isolated microorganisms in decreasing order of frequency were: $\mathrm{Aci}$ netobacter baumanni $(\mathrm{n}=27,44.2 \%)$, Pseudomonas aeruginosa $(\mathrm{n}=17,27.8 \%)$, Klebsiella pneumoniae $(\mathrm{n}=6,9.8 \%)$, K. pneumoniae and Stenotrophomonas maltophilia ( $\mathrm{n}=1,1.6 \%)$, K. pneumoniae and A. baumanni $(\mathrm{n}=1,1.6 \%), \mathrm{K}$. oxytoca $(\mathrm{n}=1,1.6 \%)$ and Enterobacter cloacae $(n=1,1.6 \%)$. In seven patients, no microorganisms were detected; however, five of these patients were colonized by carbapenem-resistant K. pneumoniae. The mean duration of colistin therapy was 12 days (range 3-45). Colistin was administered concomitantly with one of the following antibiotics: carbapenem $(n=50, \% 82)$, ampicillin-sulbactam $(n=5$, $8 \%)$, quinolones $(n=5,8 \%)$, rifampicin $(n=1,1.6 \%)$. Carbapenem was the most frequently used antibiotic. Nephrotoxicity was observed in only 1 patient, and we did not observe neurotoxicity in this study. All the patients received intravenous colistin (colisthimethate) at a dosage of $5 \mathrm{mg} / \mathrm{kg}$ daily by dividing it in three equal doses. Seven $(11.4 \%)$ patients died during the study period.

Conclusion: Colistin appears to be a safe and efficacious drug for treating MDR-GNB infections in children.

Keywords: Colistin, multidrug-resistant gram-negative infections, children

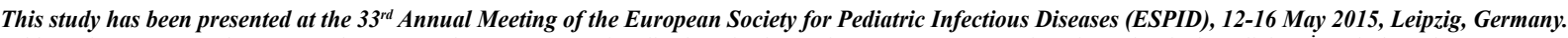
Address for Correspondence: Dr. Ahmet Soysal, Department of Pediatric Infectious Diseases, Marmara University School of Medicine, İstanbul, Turkey Phone: +90 $5324483571 \quad$ e-mail: asoysal@marmara.edu.tr Received: 6 April $2015 \quad$ Accepted: 4 December 2015 - DOI: 10.5152/balkanmedj.2016.16210 
Infections due to multidrug-resistant Gram-negative bacilli (MDR-GNB) are increasing globally. There are harmonized definitions of MDR-GNB. According to United States Food and Drug Administration (FDA), the European Committee on Antimicrobial Susceptibility Testing (EUCAST) and the Clinical Laboratory Standards Institute (CLSI) lists of antimicrobial susceptibility tests for microorganisms, MDR was described as non-sensitive to at least one agent in $\geq 3$ antimicrobial categories (1). MDR-GNB are liable for more than $50 \%$ of health-care associated infections and induces mortality rates ranging from $30 \%$ to $70 \%(2,3)$. Resistance to most classes of antibiotics result in limited therapy options and has led to reevaluate and reuse of colistin which is effective most of MDR-GNB (4). Colistin is a bactericidal drug which belongs to polymyxin group of antibiotics (5). Its use was limited because of its considerable side effects. Adverse effects of colistin use is mainly associated with nephrotoxicity. However current studies reported that this adverse effect is lesser. Although neurotoxicity is reported, studies showed this adverse effect in a less degree $(6,7)$. The data of the efficacy and safety of colistin use in children is scarce. The objectives of this study were to evaluate the clinical efficacy and safety of colistin use due to MDR-GNB infections in children.

\section{MATERIALS AND METHODS}

\section{Study design and setting}

This retrospective descriptive study was conducted in a 649-bed tertiary university hospital in Istanbul, Turkey during the period of January 2011 to November 2014.

\section{Study population}

Sixty-one children aged 0 months to 18 years old who were treated with intravenous colistin for more than 72 hours with the diagnosis of MDR-GNB infection were included in this study. The use of colistin for children is feasible after gaining the approval of the pediatric infectious diseases department.

\section{Data collection, definitions and colistin administration}

The participants were identified through the department's patient files archive, and their demographic information, underlying diseases, clinical manifestations, laboratory test results were evaluated.

Empirical intravenous colistin therapy was started to seven patients when clinical condition of patients worsened diagnosed as clinical sepsis under carbapenem therapy since five of these patients were colonized with carbapenem resistant gram negative bacilli. Clinical sepsis was identified by the presence one of the symptoms of hypotension, fever or oliguria including presence of followings: (i) no certain infection at any site, (ii) no microorganisms yielded or no blood culture obtained, and (iii) physician regulates convenient antimicrobial treatment for sepsis (8). All the other patients had culture proven infections due to MDR Gram-negative organisms.

We defined MDR-GNB as microorganisms with resistance to at least three different classes of antibiotics (9). All the isolates were resistant to carbapenems however all of them were susceptible to colistin.

We administered colistin (colistimethate sodium) $5.0 \mathrm{mg} /$ $\mathrm{kg}$ /day by dividing it into three intravenous doses (10-12). We reported our retrospective study design to the Ethics Committee of Marmara University School of Medicine and we got the document that there is no need for approval.

Clinical cure was accepted as the resolution of infectionrelated signs and symptoms 48 hours after the initiation of colistin therapy. The control blood culture results were available for all patients and all cultures were resulted as negative.

\section{Adverse events}

Nephrotoxicity was defined as an increase of $>50 \%$ from the baseline serum creatinine level to the time when treatment was initiated (13). Serum creatinine level was evaluated at least two times week. Neurotoxicity was defined as any of the following signs and symptoms after initiation of therapy; seizures, ataxia, distal paresthesias, change in mental status, dizziness and vertigo $(14,15)$.

\section{Microbiological methods}

Bacterial identification was performed using a VITEK-MS (bioMerieux; Marcy l'Etoile, France). Antibiotic Susceptibility testing for all antibiotics was done by VITEK 2 automated systems (bioMerieux; Marcy l'Etoile, France) and disk diffusion method. Minimum inhibitory concentrations (MIC) of carbapenems and colistin were determined using E-test (bioMèrieux; Marseille, France) following the manufacturer's recommendations. All carbapenems interpreted in accordance Clinical and Laboratory Standards Institute guideline (16). For colistin, EUCAST criteria was used (17).

\section{Statistical analysis}

For the statistical analyses, we documented all the available medical information including age, gender, intensive care unit (ICU) stay, underlying diseases, type of infection, isolated microorganism, mortality, concomitant antibiotic use in the Microsoft Excel. The statistical analyses of mean and median age of the patients were performed with Statistical Package for the Social Sciences version 12.0 software (SPSS Inc.; Chicago, IL, USA). 


\section{RESULTS}

Of the 61 children in the study, 29 (48\%) females and 32 (52\%) males with a mean \pm standard deviation (SD) age of $61 \pm 9$ months (range 0-216, median 12 months) received IV colistin due to MDR-GNB infections. 54 patients received IV colistin with proven MDR-GNB infections. In seven patients we did not detect any microorganisms, however five of these patients were colonized with carbapenem resistant. The mean duration of the colistin therapy was 12 days (range 3-45 days).

The risk factors evaluated as remarkable for nosocomial infections in this study were: intensive care unit stay, mechanical ventilation, presence of a central venous catheter and nasogastric tube placement. Forty $(65.5 \%)$ patients were in intensive care unit. Use of mechanical ventilation, central venous catheter and nasogastric tube were $37.7 \%, 26.2 \%$ and $26.2 \%$, respectively. Table 1 showed the risk factors for nosocomial infections.

The most common underlying disease was chronic neurological disease $(n=18,29.5 \%)$, followed by chronic pulmonary disease $(n=10,16.3 \%)$ and prematurity $(n=10,16.3 \%)$. The most causative pathogens were Acinetobacter baumannii (A. baumannii) ( $\mathrm{n}=27,44.2 \%)$, Pseudomonas aeruginosa $(P$. aeruginosa) $(\mathrm{n}=17,27.8 \%)$ followed by Klebsiella pneumoniae $($ K. pneumonia $)(\mathrm{n}=6,11.4 \%)$, Klebsiella oxytoca $(K$. oxytoca) (1.6\%) and Enterobacter cloacae (E. cloacae) (1.6\%). In two patients coinfections were detected as $K$. pneumoniae with Stenotrophomonas maltophilia (S. maltophilia) and $K$. pneumoniae with $A$. baumannii. The site of infections in decreasing order of frequency were bacteremia $(n=23,37.7 \%)$, pneumonia $(n=19,31 \%)$, wound infections $(n=6,9.8 \%)$, urinary tract infections $(n=5,8.1 \%)$ and meningitis $(n=1,1.6 \%)$. In seven patients IV colistin was started with the diagnosis of clinical sepsis. Table 2 showed type of infection, causative pathogen and the pattern of resistance.

Colistin was administered concomitantly with one of the following antibiotics; carbapenem $(n=50,82 \%)$, ampicillinsulbactam $(n=5,8 \%)$, quinolones $(n=5,8 \%)$, or rifampicin $(n=1,1.6 \%)$, however carbapenem was the most frequently used antibiotic. The mean duration of colistin therapy was 12 days (range 3-45). In all our patients we administered colistimethate sodium $5 \mathrm{mg} / \mathrm{kg} /$ day by dividing it into three intravenous doses.

The colistin therapy success rate found to be $89 \%$ since 7 (11.4\%) patients died during IV colistin treatment with the diagnosis of three patients with pneumonia (two of them with $P$. aeruginosa, one with $A$. baumannii), 2 patients with wound infections (one with A. baumannii and one with P. aeruginosa), one patient with bacteremia (with $K$. pneumoniae) and one patient with clinical sepsis. All of the deaths were accepted to be related with the infections.

Nephrotoxicity was observed in only one patient who was treated concomitantly with meropenem. The patient was followed-up by nephrology department and the dosage of the

TABLE 1. The Risk factors for nosocomial infections.

\begin{tabular}{|c|c|c|c|c|c|c|}
\hline The Risk Factors & $\begin{array}{l}\text { Bacteremia } \\
\quad(\mathrm{n}=23)\end{array}$ & $\begin{array}{l}\text { Pneumoniae } \\
\quad(\mathrm{n}=19)\end{array}$ & $\begin{array}{l}\text { Wound infections } \\
\qquad(\mathrm{n}=6)\end{array}$ & $\begin{array}{c}\text { Urinary tract } \\
\text { infections }(\mathrm{n}=5)\end{array}$ & $\begin{array}{l}\text { Meningitis } \\
(\mathrm{n}=1)\end{array}$ & $\begin{array}{c}\text { Clinical sepsis } \\
\quad(\mathrm{n}=7)\end{array}$ \\
\hline Intensive Care Unit & 17 & 9 & 4 & 3 & - & 7 \\
\hline Mechanical ventilation & 8 & 8 & 3 & 1 & - & 3 \\
\hline Presence of central venous catheter & 11 & 2 & 2 & - & 1 & - \\
\hline Presence of nasogastric tube & 4 & 3 & 2 & 1 & - & 6 \\
\hline
\end{tabular}

n: number of patients

TABLE 2. Type of infection (n), causative pathogen and the pattern of resistance

\begin{tabular}{|c|c|c|c|c|c|c|c|}
\hline Microorganisms & $\begin{array}{l}\text { The Pattern } \\
\text { of Resistance }\end{array}$ & Bacteremia & Pneumoniae & $\begin{array}{c}\text { Wound } \\
\text { infections }\end{array}$ & $\begin{array}{l}\text { Urinary tract } \\
\text { infections }\end{array}$ & Meningitis & $\begin{array}{c}\text { Clinical } \\
\text { sepsis }\end{array}$ \\
\hline A. baumannii & MDR & 16 & 5 & 3 & 2 & 1 & - \\
\hline P. aeruginosa & MDR & 1 & 12 & 3 & 1 & - & - \\
\hline K. pneumoniae & MDR & 4 & - & - & 2 & - & - \\
\hline K. oxytoca & MDR & 1 & - & - & - & - & - \\
\hline E. cloacae & MDR & 1 & - & - & - & - & - \\
\hline K. pneumoniae with S. maltophilia & MDR & - & 1 & - & - & - & - \\
\hline K. pneumoniae with A. baumannii & MDR & - & 1 & - & - & - & - \\
\hline TOTAL & - & 23 & 19 & 6 & 5 & 1 & 7 \\
\hline
\end{tabular}

MDR: multi-drug resistant; A. baumannii: Acinetobacter baumannii; P. aeruginosa: Pseudomonas aeruginosa; K. pneumoniae: Klebsiella pneumoniae; K. oxytoca: Klebsiella oxytoca; E. cloacae: Enterobacter cloacae; S. maltophilia: Stenotrophomonas maltophilia 
colistin was adjusted according to creatinine clearance, however the patient died during the treatment with the diagnosis of end-stage cystic fibrosis. A transient elevation in hepatic transmaminases during treatment with IV colistin was observed in two patients. The first patient was treated concomitantly with ampicillin-sulbactam and the second patient was treated concomitantly with imipenem which can be the causes of elevated hepatic transmaninases. Laboratory findings returned to baseline in both patients without cessation of colistin therapy. One of the other adverse effect that we have observed during the treatment was diarrhea which lasted in few days. The antibiotics used in conjunction with colistin were ciprofloxacin and linezolid. We think that these agents may be responsible of diarrhea. We have not observed neurotoxicity in our patients.

\section{DISCUSSION}

In this study, we report favorable clinical outcomes in a group of 61 children who were treated with IV colistin. This study, which is one of the largest series of colistin therapy in children, showed $89 \%$ cure rate. We find that it was an effective and well tolerated antimicrobial agent by the children patients. Few studies have investigated the clinical efficacy and safety of colistin use in children. It has been reported in previous studies that the effectiveness rates with colistin therapy were $47-88 \%$ $(15,18-20)$.

In our study, $89 \%$ patients were cured, which is consistent with previous studies; the infection-related mortality rate was $11 \%$. Furtado reported the lowest effectiveness rate with colistin therapy for the treatment of nosocomial pneumonia due to MDR - P. aeruginosa (18). In our study, 7 patients died during the therapy and the most common diagnosis was pneumoniae in three patients and the most common identified microorganism was $P$. aeruginosa in three patients.

The optimum dose for colistin is unclear. Colistin is in use as colistin sulfate and colisthimethate sodium (CMS) but only CMS which is a prodrug is available for intravenous use. There are two trading formulations of CMS that are differently formulated in vials. One of them contains $150 \mathrm{mg}$ colistin base activity, and the other one contains 1 and 2 million international units of CMS. According to published recommendations we have administered $5 \mathrm{mg} / \mathrm{kg} /$ day of colistimethate sodium into three equal doses $(15,21)$.

Previous studies have suggested that a loading dose is effective $(22,23)$. On the other hand, cumulative colistin dose was found in association with toxicity in different studies $(24,25)$. We did not administer colistin loading dose to our patients. We think that, more studies are needed to clarify suitable dose and interval of colistin and if a loading dose is essential.
Colistin was administered concomitantly with one of the following antibiotics in our study; carbapenem $(\mathrm{n}=50, \% 82)$, ampicillin-sulbactam $(n=5,8 \%)$, quinolones $(n=5,8 \%)$, or rifampicin $(\mathrm{n}=1,1.6 \%)$. The ultimate antibacterial activity and the synergy were regarded with the combination of colistin and meropenem therapy (26), for this reason carbapenem was the most frequently used antibiotic in our study. However in some cases because of different indications, we had to use quinolones despite we did not use preferential this agent under 18 years old. The patients treated with quinolones were as follows: a 17-year-old-boy with wound infection, 13 yearold-girl with pneumoniae, 12 year-old-boy with bacteremia, 9 year-old-girl with urinary tract infection and a newborn girl with bacteremia. All the patients had underlying diseases such as immunodeficiency, chronic pulmonary disease, neurological disease, malignancy and congenital heart disease, respectively. These were the available data for the patients who used quinolones. A. baumannii was responsible four of these infections and $P$. aeruginosa was the causative agent of pneumoniae. Therefore, the combination therapies may help to get high cure rates.

In previous reports, nephrotoxicity was the most common adverse effect of colistin therapy $(18,20,24)$; however, recent studies reported lower nephrotoxicity rates in association with colistin use $(14,27)$. In our study, we observed nephrotoxicity only in one patient which is similar to report of Falagas et al. (27) in 2009. We explain lower rates of nephrotoxicity with colistin therapy due to understanding of pharmacokinetics, pharmacodynamics of the agent, close monitoring of renal functions and advances of intensive care unit monitoring. Also, no neurotoxicity was observed in this study similar to previous studies in the literature $(27,28)$.

Limitations of this study were; firstly, number of the patients in this study is not enough to generalize the efficacy and adverse effects of colistin therapy. Secondly, it was a retrospective study and there was no control group to compare the efficacy and safety of colistin versus other antimicrobial agents. Thirdly, it was difficult to evaluate the adverse effect of neurotoxicity in patients who were sedated and premature. Fourthly, the drug level was not monitored. And lastly, because of this retrospective study, the microbiological findings could be described as possible as accessible, therefore we could not present the all susceptibility results.

In conclusion, colistin was well tolerated by children and it appears to be a good choice for the treatment of MDR-GNB infections. Combination therapy may achieve high cure rates and is advised for MDR-GNB infections. The studies which indicate lesser adverse effects of colistin therapy can lead gradual increase in reuse. 
Ethics Committee Approval: Ethical exemption document was received for this study from the ethics committee of Marmara University School of Medicine.

Informed Consent: Informed consent was obtained from the parents of the patients who participated in this study.

Peer-review: Externally peer-reviewed.

Author contributions: Concept - A.S., A.K., M.B.; Design A.S., A.K., M.B.; Supervision - A.S., M.B.; Resource - A.S., A.K., E.Ç., E.K.K., M.B.; Materials - S.A., G.A., N.Y., S.Ö.D., A.K.; Data Collection and/or Processing - A.K., E.K.K., S.A., E.Ç.; Analysis and/or Interpretation - A.K., E.K.K., E.Ç., A.S.; Literature Search - A.K., A.S.; Writing - A.K., A.S.; Critical Reviews - A.S., M.B.

Conflict of Interest: No conflict of interest was declared by the authors.

Financial Disclosure: The authors declared that this study has received no financial support.

\section{REFERENCES}

1. Magiorakos AP, Srinivasan A, Carey RB, Carmeli Y, Falagas ME, Giske CG, et al. Multidrug-resistant, extensively drugresistant and pandrug-resistant bacteria:an international expert proposal for interim standard definitions for acquired resistance. Clin Microbiol Infect 2012;18:268-81. [CrossRef]

2. Rice LB. Federal funding for the study of antimicrobial resistance in nosocomial pathogens: no ESKAPE. J Infect Dis 2008;197:1079-81. [CrossRef]

3. Perl TM, Dvorak L, Hwang T, Wenzel RP. Long-term survival and function after suspected Gram-negative sepsis. JAMA 1995;274:338-45. [CrossRef]

4. Falagas ME, Karageorgopoulos DE, Nordmann P. Therapeutic options for infections with Enterobacteriaceae producing carbapenem-hydrolyzing enzymes. Future Microbiol 2011;6:65366. [CrossRef]

5. Falagas ME, Kasiakou SK. Colistin: the revival of polymyxins for the management of multidrug-resistant gram-negative bacterial infections. Clin Infect Dis 2005;40:1333-41. [CrossRef]

6. Spapen H, Jacobs R, Van Gorp V, Troubleyn J, Honoré PM. Renal and neurological side effects of colistin in critically ill patients. Ann Intensive Care 2011;1:14. [CrossRef]

7. Yahav D, Farbman L, Leibovici L, Paul M. Colistin: new lessons on an old antibiotic. Clin Microbiol Infect 2012;18:18-29. [CrossRef]

8. Garner JS, Jarvis WR, Emori TG, Horan TC, Hughes JM. CDC definitions for nosocomial infections. Am J Infect Control 1988;16:128-40. Erratum in: Am J Infect Control 1988;16: 177. [CrossRef]
9. Falagas ME, Karageorgopoulos DE. Pandrug resistance (PDR), extensive drug resistance (XDR), and multidrug resistance (MDR) among gram-negative bacilli: Need for international harmonization in terminology. Clin Infect Dis 2008;46:1121-2. [CrossRef]

10. Li J, Nation RL, Turnidge JD, Milne RW, Coulthard K, Rayner $\mathrm{CR}$, et al. Colistin: the re-emerging antibiotic for multidrugresistant gram-negative bacterial infections. Lancet Infect Dis 2006;6:589-601. [CrossRef]

11. X-Gen Pharmaceuticals Inc. Colistimethate for injection, USP: for intramuscular and intravenous use. [Accessed April 9, 2010]; Available from: http://x-gen.us/wp-content/uploads/2014/03/ Colistimethate_pi.pdf

12. European Medicines Agency completes review of polymyxinbased medicines. (Published in 24/10/2014); Available from: http://www.ema.europa.eu/docs/en_GB/document_library/ Press_release/2014/10/WC500176334.pdf

13. Falagas ME, Sideri G, Vouloumanou EK, Papadatos JH, Kafetzis DA. Intravenous colistimethate (Colistin) use in critically Ill children without cystic fibrosis. Pediatr Infect Dis J 2009;28:123-7. [CrossRef]

14. Cheng CY, Sheng WH, Wang JT, Chen YC, Chang SC. Safety and efficacy of intravenous colistin (colistin methanesulphonate) for severe multidrug-resistant gram-negative bacterial infections. Int J Antimicrob Agents 2010;35:297-300. [CrossRef]

15. Karbuz A, Özdemir H, Yaman A, Kocabaş BA, Ödek C, Güriz H, et al. The use of colistin in critically Ill children in a pediatric intensive care unit. Pediatr Infect Dis J 2014;33:19-24. [CrossRef]

16. Clinical and Laboratory Standards Institute. Performance standards for antimicrobial susceptibility testing: twenty-first informational supplement M100-S21. Wayne, PA, USA: CLSI; 2011.

17. The European Committee on Antimicrobial Susceptibility Testing (EUCAST). Clinical MIC breakpoints. Available from: http://www.eucast.org/clinical_breakpoints.

18. Furtado GH, d'Azevedo PA, Santos AF, Gales AC, Pignatari $\mathrm{AC}$, Medeiros EA. Intravenous polymyxin B for the treatment of nosocomial pneumonia caused by multidrug-resistant Pseudomonas aeruginosa. Int J Antimicrob Agents 2007;30:315-9. [CrossRef]

19. Falagas ME, Vouloumanou EK, Rafailidis PI. Systemic colistin use in children without cystic fibrosis: a systematic review of the literature. Int J Antimicrob Agents 2009;33:503. [CrossRef]

20. Ouderkirk JP, Nord JA, Turett GS, Kislak JW. Polymyxin B nephrotoxicity and efficacy against nosocomial infections caused by multiresistant Gram-negative bacteria. Antimicrob Agents Chemother 2003;47:2659-62. [CrossRef]

21. Nation RL, Li J. Polymyxins. In: The Use of Antibiotics, Kucers A. editor. London: Heinemann; 2010:955. [CrossRef]

22. Plachouras D, Karvanen M, Friberg LE, Papadomichelakis E, Antoniadou A, Tsangaris I, et al. Population pharmacokinetic analysis of colistin methanesulfonate and colistin after intravenous administration in critically ill patients with infections caused by gram-negative bacteria. Antimicrob Agents Chemother 2009;53:3430-6. [CrossRef] 
23. Dalfino L, Puntillo F, Mosca A, Monno R, Spada ML, Coppolecchia $\mathrm{S}$, et al. High-dose, extended-interval colistin administration in critically ill patients: is this the right dosing strategy? A preliminary study. Clin Infect Dis 2012;54:1720-6. [CrossRef]

24. Hartzell JD, Neff R, Ake J, Howard R, Olson S, Paolino K, et al. Nephrotoxicity associated with intravenous colistin (colistimethate sodium) treatment at a tertiary care medical center. Clin Infect Dis 2009;48:1724-8. [CrossRef]

25. Falagas ME, Rizos M, Bliziotis IA, Rellos K, Kasiakou SK, Michalopoulos A. Toxicity after prolonged (more than four weeks) administration of intravenous colistin. BMC Infect Dis 2005; 5:1. [CrossRef]
26. Ziad Daoud, Najwa Mansour, Khalil Masri. Synergistic Combination of Carbapenems and Colistin against P. aeruginosa and A. baumannii. J Med Microbiol 2013;3:253-8. [CrossRef]

27. Falagas ME, Sideri G, Vouloumanou EK, Papadatos JH, Kafetzis DA. Intravenous colistimethate (colistin) use in critically ill children without cystic fibrosis. Pediatr Infect Dis J 2009;28:123-7. [CrossRef]

28. Kapoor K, Jajoo M, Dublish S, Dabas V, Gupta S, Manchanda $\mathrm{V}$. Intravenous colistin for multidrug-resistant gram-negative infections in critically ill pediatric patients. Pediatr Crit Care Med 2013;14:268-72. [CrossRef] 